\title{
Presentation and Management of Bulky Adrenal Tumors in Khartoum
}

\author{
Sharfi $\mathrm{AR}^{1 *}$, Fadalla $\mathrm{AI}^{2}$, Elmegboul $\mathrm{MA}^{3}$, Nour $\mathrm{SM}^{2}$, Abdalla $\mathrm{AA}^{4}$, \\ Zulfo $\mathrm{N}^{2}$, Sinada $\mathrm{A}^{5}$ and Abdalla $\mathrm{S}^{3}$ \\ ${ }^{1}$ Department of Urology, Soba University Hospital, Sudan \\ ${ }^{2}$ Consultant Urologist, Soba University Hospital, Sudan \\ ${ }^{3}$ Specialist Urologist, Soba University Hospital, Sudan \\ ${ }^{4}$ Senior Registrar in Urology, Soba University Hospital, Sudan \\ ${ }^{5}$ Consultant Anethiologist, Soba University Hospital, Sudan
}

*Corresponding author: Abdel Raof A Sharfi, Consultant Urologist and Head Department of Urology, Soba University Hospital, Khartoum, PO Box: 7264, Sudan, Email: sharfi80@hotmail.com

\section{Abstract}

Introduction: The detection of adrenal masses, especially pheochromocytoma needs a high index of suspension. All patients with symptoms or signs suggestive of pheochromocytoma need thorough investigations. Patients with pheochromocytoma have a potentially curable cause for hypertension, but if undetected, pheochromocytoma presents a high risk of morbidity and mortality.

\section{Objectives to Assess:}

The modes of presentation of adrenal masses.

The available methods of investigations.

The options of surgical treatment.

Results: Seventy-two patients were treated in the urology unit of Soba University hospital in Khartoum in the period from 1996 to 2017. The mean age was 32 years. The male to female ratio was 1 to 2.7. CT abdomen was diagnostic in 93.1 percent. The commonest tumor was pheochromocytoma occurring in $75 \%$, followed by adrenal carcinoma in $11.2 \%$ then benign tumors in $6.8 \%$ and others in $7.0 \%$. All patients underwent open surgical adrenalectomy. The mortality rate was $1.4 \%$. Other complications are discussed in the text.

Discussion: CT abdomen has a sensitivity of $100 \%$ in diagnosing adrenal masses. This sensitivity reduces to about $93 \%$ in detecting extra adrenal tumors. Although open surgical adrenalectomy remains a very effective method of treatment of bulky pheochromocytoma, laparoscopic adrenalectomy is becoming a good alternative to open surgery.

Keywords: Pheochromocytoma; Adrenalectomy; Laparoscopy; Adrenal Carcinoma; Catecholamine's 
Abbreviations: VMA: Vinyl Mandelic Acid; CT: Computed Tomography.

\section{Introduction}

The two main concerns with regard to adrenal masses are:

- Whether it is hormonally active (functional).

- Whether it is malignant.

Benign adrenal cortical adenomas are commonly smaller than $6 \mathrm{~cm}$ in diameter on initial presentation, but they can be larger [1]. The treatment for hormonally active adrenal tumors is surgery [2]. In this study we present a series of patients with bulky adrenal tumors (tumors $9 \mathrm{~cm}$ or larger in diameter) with special emphasis on pheochromocytoma. All patients with any of the following symptoms or signs were investigates for pheochromocytoma:

- Patients requiring more than four medications to control their blood pressure.

- Patients with onset of hypertension before the age of 35 or above the age of 60 years.

- Patients with other symptoms or signs suggestive of pheochromcytoma.

\section{Objectives to Assess}

- Frequency of bulky adrenal tumors in Khartoum.

- Modes of presentation of bulky adrenal tumors.

- Available methods of investigations.

- Methods of surgical treatment.

\section{Patients and Methods}

This is a hospital based descriptive study carried out in the urology unit of Soba University hospital in Khartoum -Sudan- in the period from Jan 1996 to Dec 2017. All patients presenting with symptoms or signs of pheochromcytoma or discovered to have adrenal tumors incidentally were included in the study. All had detailed history taken, physical examination with special emphasis of frequent blood pressure recording at different times of the day. Investigations included urinalysis, Vinyl Mandelic Acid (VMA) measurements, renal function tests, chest Xray, ECG, abdominal Ultrasonography and computed tomography of the abdomen. Selective angiography and MRI were added in few patients with suspected extra adrenal tumors.

All the 72 patients in this study had surgical treatment in the same urology unit at Soba hospital by one group of surgeons. There was close collaboration between the physician endocrinologist, the anethiologist and the urologist. All the patients with pheochromocytoma were started on an alpha blocker (Pheoxybenzamine tablets) two weeks prior to surgery. Beta blockers were added in few patients with severe tachycardia .Blood was prepared for all patients. All the patients with pheochromocytoma had invasive arterial line monitoring with a transducer. Central venous line was established following induction of anesthesia. A short acting alpha blocker was kept ready to compact with possible fluctuations of blood pressure during induction of anesthesia, positioning of patient, and during manipulation of the tumor. Blood pressure and other vital signs were monitored continuously during and in the post-operative period. The surgical approach for adrenalectomy was a posterior approach through the elevens intercostals space retero-peritoneally with the patient in the kidney position. All the surgically removed adrenal tumors were sent for histological examination. The follow up was for one year with review of recurrent symptoms or signs.

\section{Results}

A total of 72 patients were included in this study. Their ages ranged between 12 and 52 with a mean of 32 years. There were 52 females and 20 males with a male to female ratio of 1 to 2.7. The commonest presenting symptom was hypertension occurring in 42 patients (58.3\%), followed by headache in 16 patents $(22.2 \%)$, blurring of vision in $8(11.1 \%)$, loin pain in $4(5.6 \%)$, while it was incidental finding during abdominal CT for other reasons in 2 patients $(2.8 \%)$. Twelve patients $(16.7 \%)$ gave past history of diabetes and 4 (5.6\%)were asthmatic. Clinical examination prior to surgery revealed palpable adrenal mass in two patients $(2.8 \%)$ with malignant adrenal tumors. Three female patients (4.2\%) had simple multinodular goitre. Severe papilledema was detected in 4(5.6\%) young patients.

Computed tomography (CT) of the abdomen was diagnostic in 67patients $(93.1 \%)$ including the incidentally detected cases. The $\mathrm{Ct}$ abdomen could locate the anatomical site, the size as well as commenting on the kidneys and other abdominal organs especially in cases of malignant adrenal tumors. Abdominal Ultrasonography was performed in 52 patients $(72.0 \%)$, VMA in 6 patients (8.3\%), MRI in $4(5.6 \%)$ with recurrent tumors, while selective angiography was performed in one patient $(1.4 \%)$ with difficult to locate the anatomic site of a recurrent tumor. Chest X-ray showed cariomegaly in 4 patients (5.6\%). Fifty-two (72.2\%) of the tumors were on the right side in close proximity to the upper pole of the right kidney, $16(22.2 \%)$ were on the left side while 4 (5.6\%) were bilateral. 
All the 72 patients $(100 \%)$ underwent open surgical adrenalectomy as the sole method of treatment. The surgical approach was posterior retroperitoneal through the 11th intercostals space in 68 patients $(94.4 \%)$, while it was transperitoneal in 4 patients $(5.6 \%)$ with bilateral tumors. There were 8 post-operative complications (11.1\%). The mortality was one $(1.4 \%)$ in a patient with bulky adrenal carcinoma invading the upper pole of the left kidney. other complications included recurrence within 6 months in 5 patients $(6.9 \%)$, spleenectomy in 0ne (1.4\%), and severe post-operative hypotension in 4 patients (5.6\%) who received beta blocker as well as a short acting alpha blocker intra operatively. The blood pressure was back to normal in the immediate postoperative period in 8 patients $(11.1 \%)$, while it was back to normal in all the other patients within seven to ten post-operative days .Four patients (5.6\%) developed severe hypotension in the immediate postoperative period but could be resumed with adequate intravenous normal saline. Two of the four patients with papilledema resumed their vision within two weeks while it resolved gradually in the other two patients within six weeks. The VMA was back to normal within ten to fifteen days postoperatively. The histology of the tumors showed pheochromocytoma in 54 patients $(75.0 \%)$, adrenal carcinoma in $8(11.1 \%)$, benign tumors in $5(6.9 \%)$, adrenal hyperplasia in 3 (4.2\%) and tuberculosis in 2 patients $(2.8 \%)$.

\section{Discussion}

Most of the patients in this study were of young age groups with a mean of 32 years. On the contrary Eisenhower, et al. reported a mean age of 50 years in patients with pheochromocytoma, while in the group with non-secreting tumors, the mean age was 42 years at the time of diagnosis. In their study which included 172 patients, pheochromocytoma tumors were diagnosed eleven years later than those with non-epinephrine producing tumors. Neumannet, et al. [3] and Manelli, et al. [4] showed that age at diagnosis varies according to tumor catecholamine phenotype. They showed that earlier age at diagnosis is hereditary than sporadic. In the current study we couldn't document hereditary link with age at presentation. There were more females than males in this study making a male to female ratio of 1 to 2.7. This is in agreement with reports by Grunbach, et al. [5] and Kloos, et al. [6]. One of the possible explanations of females being affected more than males could be attributed to the fact that females have more opportunities to receive abdominal CT compared to males. In this study most of the adrenal tumors occurred on the right side. Jonson, et al. [7] reported that the left side was affected more the right side. In the current study bilateral tumors constituted only $5.6 \%$, while in other reports approximately $10 \%$ of the adrenal tumors were bilateral $[8,9]$.

In this study CT abdomen was diagnostic in $93.1 \%$. In other studies $[10,11]$ the sensitivity in detecting pheochromocytoma ranged between 93 to $100 \%$. They showed that sensitivity of CT decreases to approximately $90 \%$ for extra-adrenal pheochromocytoma [12]. Other studies showed MRI to be superior to CT for detecting extra- adrenal tumors $[13,14]$. The majority of the bulky tumors $(75.0 \%)$ in this study were pheochromocytoma; however pheochromocytoma was reported to occur in only $8 \%$ in other series [15]. Some studies showed chances of having a malignant tumor correlates directly with the size of the tumor [16]. This can be explained at least in part by the fact that most of the patients in this study presented late giving more chances for the tumor to grow bigger. Incidental finding of adrenal tumor in this study was $2.8 \%$. Other studies showed incidence of up to $4.0 \%$ in patients undergoing CT abdomen for other reasons [17]. All the patients in this study underwent open surgical adrenalectomy as the sole method of treatment. Surgery for pheochromocytoma entails several considerations. Induction of anesthesia before surgery, positioning of the patient and manipulation of the tumor or other stimulation can cause massive outpouring of catecholamines from the tumor resulting in hypertensive crisis, stroke or myocardial infarction.

To prevent these symptoms, patients with pheochromocytoma must undergo pharmacological blockade of catecholamine synthesis with phenoxybenzamine (an alpha adenceptor blocker) [1821]. The operative approach in the majority of the patients in this study was posterior retroperitoneal through the 11th intercostals space, while open surgery was performed through a transperitoneal approach in only 4 patients with bilateral tumors. The survival rates in this study were $98.6 \%$. In other studies the survival rates following open transperitoneal approach ranged between 97.7 to $100 \%$ [22-24]. Development of laparoscopic surgical techniques has provided an alternative to open surgical procedures [25-27]. It was shown by some authors that both open surgery and laparoscopic surgery have similar blood loss and complications [28,29]. Others reported that laparoscopic adrenalectomy is the preferred procedure for lesions smaller than $8 \mathrm{~cm}[30,31]$. No randomized trials have compared open surgery versus laparoscopic adrenalectomy, however open surgery is performed for bilateral tumors, large masses (masses more than $10 \mathrm{~cm}$, for possible malignant disease and 
pheochromocytoma [32,33]. As this study involved mainly bulky tumors (more than $9 \mathrm{~cm}$ in diameter) most of which were pheochromcytoma, all were treated with open surgery, besides that laparoscopic surgery was not well established in this unit at the time of starting this study. We look forward to see the role of laparoscopy in bulky pheochromocytoma.

\section{Conclusion}

Diagnosis of adrenal tumors, especially the pheochromocytoma entails a high index of suspension in all patients with hypertension, or other symptoms or signs suggestive of pheochromocytoma. Their management entails a close collaboration between the endocrinologist, the cardiologist, the anethiologist and the urologist. With advances in imaging, incidentaloma is expected to be detected more. With advances in laparoscopic techniques the future can witness treating bulky adrenal pheochromocytoma with laparoscopy.

\section{References}

1. Menegaux F, Cherau N, Peix JL, Christon N, Lifante JC, et al. (2014) Management of adrenal incidenteloma. J Visc Surg 151(5): 355-364.

2. Yener S, Ertilars S, Secil M, Demir T, Akinci B, et al. (2010) Prospective evaluation of tumor size and hormonal status in adrenal tumors. J Endocrinol Invest 33(1): 32-36.

3. Neumann HP, Bausch B, McWhiney SR, Bender BV, Gimn 0, et al. (2002) Germ line in non-syndromic pheochromocytoma. N Eng J Med 346(19): 14591466.

4. Minnelli M, Casellano M, Sghiavi F, Filetti S, Giacche M, et al. (2009) Clinically guided genetic screening in a large cohort of Italian patients with pheochromocytoma and functional or non-functional paragangionoma. J Clin Endocrinol Metab 94(5): 1541-1547.

5. Grumbach MM, Biller BM, Braunstein GD, Campbell KK, Carney JA, et al. (2003) Management of clinically in apparent adrenal masses. Ann Intern Med 138(5): 424-429.

6. Kloos RT, Gross MD, Francis IR, Korobkin M, Shapiro B (1995) Incidentally discovered adrenal masses. Endocr Rev 16(4): 460-484.
7. Kim J, Bae KH, Choi YK, Jeong JY, Park KG, et al. (2013) Clinical characteristic of 348 patients with adrenal masses. Endocrinol Metab March 28(1): 20-25.

8. Thompson LD (2002) Pheochromocytoma of the adrenal gland. Scaled Score (PASS) to separate benign from malignant neoplasms: a clinicopathologic and immune-phenotypic study of 100 cases. Am J Surg Pathol 26(5): 551-566.

9. Brunt LM, Moley JF (2001) Adrenal incidentaloma. Worm J Surg 25: 905-13.

10. Goldstein RE, O'Neill JA, Holcomb GW, Morgan MW, Nebkett WW, et al. (1999) Clinical experience over 48 years with pheochromocytoma. Ann Surg 229(6): 764-766.

11. Francis IR, Korobkin M (1996) Pheochromocytoma. Radiology Clin North Am 34: 1101-12.

12. Mannelli M, Ianni L, Cilotti A, Continu A (1999) Pheochromocytoma in Italy: a multicentric retrospective study. Eur J Endocrinol 141(6): 619624.

13. Kazaryan AM, Mala T, Edwin B (2001) Does tumor size influence the outcome of laparoscopic adrenalectomy?. Laparoendosc Adv Surg Tech A 11(1): 1-4.

14. Mansmann G, Lau J, Balk E, Rothberg M, Miyalli Y, et al. (2004) The clinically in apparent adrenal mass: update in diagnosis and management. Endocrinol Rev 25(2): 309-340.

15. Bertherat J, Mosnier-Pudar H, Bertagna X (2002) Adrenal incidentalomas. Curr Opin Oncol 14(1): 5863.

16. Walther MM, Keiser HR, Linehan WM (1999) Pheochromocytoma: evaluation, diagnosis and treatment. World J Urol 17: 35-39.

17. Pullerits J, Ein S, Balfe JW (1988) Anaethesia for pheochromocytoma. Can J Anaethesia 35(5): 526533.

18. Levine SN, McDonald JC (1984) The evaluation and management of pheochromocytoma. Adv Surg 17: 281-313.

19. Wang C, Yu R (2010) Preoperative preparation for pheochromocytoma resection: physician survey and 
clinical practice. Exp Cli Endocrinol Diabetes 118(7): 400-404.

20. Kwon SY, Lee KS, Lee JN (2016) Risk factors for hypertensive attacks during pheochromocytoma resection. Investing Cli Urol 57(3): 184-190.

21. Modin IM, Frandon JR, Sheperd A, Johnston ID, Icennedy TL, et al. (1979) Pheochromocytoma in 72 patients: clinical and diagnostic features, treatment and long term results. Br J Surg 66(7): 456-465.

22. Cusack JC, Phitayakorn R (2014) The management of pheochromocytoma. In: Cameron JL \& Cameron AM (Eds.), Current surgical therapy, 11th (Edn.), Philadelphia, PA: Elsevier Saunders, pp: 636-642.

23. Pecak K, Timmer HJLM, Elsenhofer G (2016) Pheochromocytoma. In: Jameson JL, et al. (Eds.), Endocrinology: adult and pediatric. $7^{\text {th }}$ (Edn.), Philadelphia PA: Elsevier Saunders, pp: 110-116.

24. Orchard T, Grant CS, Va Heerden JA, Weaver A (1993) Pheochromocytoma: continuous evaluation of surgical therapy. Surgery 114(6): 1153-1159.

25. Thompson GB, Grant CS, Van Heerden JA, Schlinkert RT, Young WF Jr, et al. (1997) Laparoscopic versus open posterior adrenalectomy: a case control study of 100 patients. Surgery 122(6): 1132-1136.

26. Lee CW, Salem AI, Schneider DF, Leverson GE, Tran TB, et al. (2017) Minimally invasive resection of adenocortical carcinoma: a multi institutional study of 201 patients. J Gastrointest Surg 21(2): 352-362.
27. Brix D, Allolio B, Fenske W, Agha A, Dralle H, et al. (2010) Laparoscopic versus open adrenalectomy for adenocortical carcinoma: surgical and oncologic outcome in 152 patients. Eur Urol 58(4): 609-615.

28. Linos DA, Stylopoulos N, Boukis M, Souvatzoglou A, Raptis S, et al. (1997) Anterior, or laparoscopic approach for the adrenal disease?. Am J Surg 173(2): 120-125.

29. Nan $P$, Demyttenaere $S$, Muscarella $P$, Narula V, Hazey JW, et al. (2010) Pheochromocytoma does not increase risk in laparoscopic adrenalectomy. Surg Endoscopy 24(11): 2760-2764.

30. Liq Y, Li F (2010) Laparoscopic adrenalectomy in pheochromocytoma: retroperitoneal approach versus transperitoneal approach. J Endocrinol 24(9): 14411445 .

31. Porpiglia F, Flori C, Daffara F, Zaggia B, Bollito E, et al. (2010) Retrospective evaluation of the outcome of open versus laparoscopic adrenalectomy for stage 1 and 2 adenocortical cancer. Eur Urol 57(5): 873-878.

32. Ulchaker JC, Goldfaris DA, Bravo EL, Novick AC (1999) Successful outcome in pheochromocytoma surgery in modern era. J Urol 161(3): 764-767.

33. Walther MM, Keizer HR, Linehan WM (1999) Pheochromocytoma: evaluation, diagnosis and treatment. World J Urol 17(1): 35-39. 